Research report

\title{
Frustration and perseveration in stereotypic captive animals: Is a taste of enrichment worse than none at all?
}

\author{
Naomi Lathama,*, Georgia Mason ${ }^{\mathrm{b}}$ \\ a Zoology Department, University of Oxford, South Parks Road, Oxford OX1 3PS, UK \\ ${ }^{\mathrm{b}}$ Department of Animal and Poultry Science, University of Guelph, 50 Stone Road East, Building \#70, Guelph, Ontario, Canada N1G 2W1
}

\section{A R T I C L E I N F O}

\section{Article history:}

Received 25 July 2009

Received in revised form 2 March 2010

Accepted 8 March 2010

Available online 15 March 2010

\section{Keywords:}

Welfare

Stereotypic behaviour

Frustration

Perseveration

Stress

Negative contrast

Reward

Enrichment

\begin{abstract}
A B S T R A C T
Stereotypic behaviours are common in animals in impoverished housing, arising from two complementary processes: (1) thwarted attempts to perform motivated behaviours; (2) forebrain dysfunction impeding normal behavioural inhibition. When enriched animals are moved to impoverished housing, they are sometimes protected against developing stereotypic behaviour, but in other cases become even more stereotypic than animals housed lifelong without enrichment. Negative contrast-induced frustration must occur in both scenarios. We hypothesise that sustained behavioural responses to this frustration are prevented in the former by normalised forebrain function, but exacerbated in the latter by forebrain dysfunction. ICRCD-1 mice reared in enriched or standard cages were re-caged at 3 months to standard conditions. Here, previously-enriched mice became far more stereotypic than mice reared from birth in such conditions. To investigate the role of frustration, we assessed both corticosterone output and motivation (break-point) to regain enrichments. We also assessed perseveration via extinction learning. As predicted, previously-enriched mice were as perseverative as standard-raised mice, and frustration seemed to play a causal role in their exacerbated stereotypic behaviour. Previously-enriched mice showed higher motivations to access enrichments, and only in this group did these correlate with corticosterone levels after re-caging; furthermore only in previously-enriched mice did corticosterone responses to re-caging predict stereotypic behaviour 30 days later (males only). All results need replicating and further investigation. However, they suggest for the first time that individual risk factors related to the HPA axis predict stereotypic behaviour following enrichment-removal, and that previously-enriched mice have lasting motivational differences from standard-raised mice, suggesting sustained behavioural effects related to the frustration of enrichment-loss.
\end{abstract}

(C) 2010 Elsevier B.V. All rights reserved.

\section{Introduction}

Highly repetitive 'stereotypic behaviours' are prevalent in laboratory, farm and zoo animals: over 85 million individuals worldwide perform activities like pacing and body-rocking, and in some captive populations (e.g. zoo-housed giraffes, stall-housed pregnant sows, and single-housed laboratory primates [25]) they are nearly ubiquitous. Ethologists and neuroscientists have proposed two complementary explanations for stereotypic behaviours. Ethologists, who focus on the evolution and proximate causation of normal species-typical behaviour, explain them in terms of sustained attempts to perform highly-motivated normal behaviour patterns that are frustrated by captivity (e.g. [44]). Empirical support for this view includes the following: stereotypic digging in caged gerbils (Meriones unguiculatus) is triggered specifically by the lack of naturalistic burrow-like structures [64]; the motor patterns

\footnotetext{
* Corresponding author. Tel.: +44 01865 271234; fax: +44 01865310447

E-mail address: naomi.latham@zoo.ox.ac.uk (N. Latham).
}

involved in feather-plucking by hens (Gallus gallus) are morphologically identical to foraging pecks [9], and bar-chewing by laboratory mice (Mus musculus) develops from repeated escape-attempts [31]. Researchers from neuroscience and related disciplines [58,62] instead explain stereotypic behaviours in terms of Central Nervous System (CNS) pathologies similar to those underlying stereotypic behaviour in humans with schizophrenia or autism (e.g. $[10,59]$ ), subjects dosed with psychostimulants (see [42]), and severely maternally-deprived primates (reviewed [21]). Here, forebrain changes that compromise abilities to inhibit inappropriate responses induce stereotypic behaviour, along with perseveration 'the continuation or recurrence of an. . . activity without the appropriate stimulus' [45] - and reduced behavioural flexibility. Evidence for similar CNS impairments in caged animals includes correlations between individual levels of stereotypic behaviour and: perseveration/reduced behavioural flexibility under test (e.g. $[11,61]$ ); altered dopaminergic receptor density/binding affinities in ventral and dorsal striatum (e.g. [29,53]); reduced striatal enkephalin, a marker for indirect pathway activity [39], and reduced cytochrome oxidase activity in the substantia nigra [51]. 
Consistent with both ethological and neuroscientific accounts, captive animals' stereotypic behaviours are less prevalent and severe if individuals are raised and housed with 'enrichments', i.e. structures and stimuli that promote natural behaviour $[22,27,56,57]$, and that are now well-documented with regard to enhancing CNS functioning/delaying the onset of neurological disorders [33]. Enriched individuals may also have reduced corticosteroid output, suggesting less stress and frustration [15], and anatomical and physiological changes in cortico-basal ganglia pathways that suggest more normal CNS functioning, e.g. increased dendritic spine densities (reviewed [22]). As one would expect, animals raised in unenriched conditions but then provided with enrichment tend to show reductions in stereotypic behaviour-as demonstrated experimentally, for instance in research rodents $[4,51]$, as well as via meta-analyses of environmental enrichments' effects on zoo animals [47,49,50]. The beneficial effects of added enrichments vary in magnitude: different enrichments vary in efficacy $[47,49,50]$ and individuals vary in their responses, e.g. elderly animals' stereotypic behaviours are often resistant to enrichment $[4,14,54]$. However, the direction of effects is largely consistent: stereotypic behaviours are almost always attenuated by the addition of enrichments, and sometimes even abolished altogether.

The converse treatment - removing enrichments from animals raised with them - has, however, far more unpredictable effects. As might be expected from the accounts above, providing enrichments but then removing them often exacerbates or even induces stereotypic behaviour; for instance removing the mother often triggers stereotypic attempts to escape or suckle in young mammals (reviewed [21]), while removing or delaying expected food rewards exacerbates pacing, weaving and sham-chewing in captive pigs and carnivores $[16,23]$. Less expected is that in some of these cases, the stereotypic behaviours of animals from whom complex natural stimuli are removed become even more prevalent and severe than those of subjects that have lived without enrichment all their lives. Thus, caged birds brought in from the wild typically show more route-tracing than captive-bred conspecifics [19]; removing temporary enrichments from laboratory primates elevates stereotypic behaviours over the levels performed before they were provided (e.g. [2]), and removing straw from pigs used to interacting with it increases abnormal tail-biting above levels in pigs never provided with this enrichment [8]. Furthermore, to complicate the picture further, in yet other cases environmental enrichment can appear to protect animals against later developing stereotypic behaviour, even after its removal. Thus in many mammalian species, individuals caught from the wild and caged as adults are less stereotypic than captive-born conspecifics (reviewed [24]); while bank voles (Clethrionomys glareolus) and deer mice (Peromyscus maniculatus) reared in large, enriched cages remain less stereotypic when transferred to standard cages than conspecifics housed in such conditions all their lives $[14,34,38]$. Thus removing enrichments has inconsistent effects, variously increasing or decreasing stereotypic behaviour relative to animals exposed to life-long barren housing.

This paradox likely reflects the relative contributions of frustrated motivation and of abnormal behavioural control caused by forebrain dysfunction. Enrichment-removal is particularly frustrating: animals with experience of valuable resources are less motivationally satisfied by poor resources than are animals without such high expectations: so-called 'negative contrast' effects or 'Crespi' effects (e.g. [6,37,65]). In negative contrast paradigms frustrative non-reward (e.g. $[23,36])$ typically elevates corticosteroid output and induces behavioural activation, particularly attempts to escape and/or to perform the thwarted highly-motivated behaviour [19]. However, such effects are typically transient, these behaviours extinguishing $[18,36]$, sometimes being replaced with inactivity [3].
We therefore hypothesise that when enriched rearing protects animals against stereotypic behaviour, enrichment-removal does not lead to sustained behavioural responses indicative of frustration, despite the downshift in environmental conditions, because enriched rearing has normalised forebrain function, thereby enhancing behavioural flexibility and normalizing behavioural inhibition (see e.g. $[20,30,41])$. We term this the 'Protection Hypothesis'. Conversely, we hypothesise that when enrichmentremoval increases stereotypic behaviour (over that of subjects raised without enrichment) the enhanced frustration induced by the downshift in environmental conditions has sustained behavioural effects due to underlying deficits in forebrain function: deficits that render abnormally perseverative the resultant attempts to escape and/or perform thwarted activities. We term this the 'Frustration Hypothesis', to highlight the role frustration now plays in the exacerbation of stereotypic behaviour. Here, our aim was to test these ideas, by assessing both perseveration and frustration in mice raised with enrichments but then moved to non-enriched cages.

\section{Methods}

\subsection{Overall aims and rationale}

If the hypotheses above are correct we would expect one of the two following outcomes. Firstly, if early enrichment decreases the stereotypic behaviour our enriched-reared subjects display after transfer to non-enriched conditions compared to mice raised in such conditions then we should find that (a) frustration measured post-transfer, as inferred from corticosteroid responses $[26,68]$ and motivations to re-acquire the enrichments (cf. e.g. $[5,23,48]$ ), does not predict their performance of stereotypic behaviour, and (b) our enriched-reared subjects display more normal behavioural inhibition, as inferred from perseveration under test (e.g. [52]) - a proxy measure of basal ganglia dysfunction [11,61] - than non-enrichedraised mice ('Protection Hypothesis'). In contrast, if early enrichment increases the stereotypic behaviour our subjects display after transfer to non-enriched conditions compared to mice raised in such conditions, we should find that (a) frustration post-transfer does predict their performance of stereotypic behaviour, while (b) behavioural inhibition should be no more normal in our enriched-reared subjects than in non-enriched-raised mice ('Frustration Hypothesis'). As the first assessment of perseveration, frustration and stereotypic behaviour concomitantly in the same subjects, in addition to testing these hypotheses, our experiment also allowed us opportunistically to investigate whether frustration helps cause perseveration, and whether frustration and perseveration combine or summate to determine overall levels of stereotypic behaviour (see 'statistical analyses').

\subsection{Differential rearing and behavioural/physiological data collection during this} time

12 pregnant ICR CD-1 females at 14-16 days gestation were housed in opaque MB1 cages $(45 \mathrm{~cm} \times 28 \mathrm{~cm} \times 13 \mathrm{~cm}$, North Kent Plastics). This strain was chosen because used in previous studies of stereotypic behaviour [31,66,67], and one of the highest selling outbred mouse strains (source: Harlan UK Ltd.). All cages contained ad lib. food (RM3 pelleted food, Lillico, UK), a water bottle, wood-shaving bedding (PetsatHome) and nesting material (rough teabag nesting material, Lillico, UK). Cages with no further additions comprised the standard (STA) conditions. Half the cages additionally contained nest boxes (PetsatHome), plastic tunnels (B\&Q) and a 'novel' object chosen from a variety of commercial rodent enrichments (PetsatHome) and changed weekly': cage furnishings chosen based on the proven preference of mice for, and welfare benefits associated with, nesting material and increased environmental complexity [35]. These comprised the enriched (ENR) cages, in which six dams and their litters were housed-see Fig. 1. Lights on/off occurred at $1 \mathrm{am} / 1 \mathrm{pm}$. Room lights were shaded so that light levels were $\sim 10$ Lux at floor level during light hours. An automated dimmer provided a $1 \mathrm{~h}$ dusk period prior to lights-off, and at night the room was lit by a $25 \mathrm{~W}$ red bulb. Temperature and humidity were maintained at $20^{\circ} \mathrm{C}\left( \pm 2{ }^{\circ} \mathrm{C}\right)$ and $50-70 \%$, respectively, and animals were checked daily. Cages were not cleaned until 2 weeks after the birth of litters to minimise disturbance. After this, bedding and nesting materials were changed weekly, and cages cleaned out and washed every 4 weeks.

Weaned pups (male $N=24$; female $N=24$ ) were then individually-housed in cages matching their natal conditions, and kept there into young adulthood (89 days). Individual housing was opted for here to (a) try and minimise 'litter effects' while also using all pups produced (to avoid wasting surplus animals), (b) eliminate social hierarchy effects [31] that may have adversely influenced our ability (to detect each individual's underlying predisposition to frustration and perseverative tendencies), and (c) allow the in-cage assessment of motivation and perseveration (see below) 

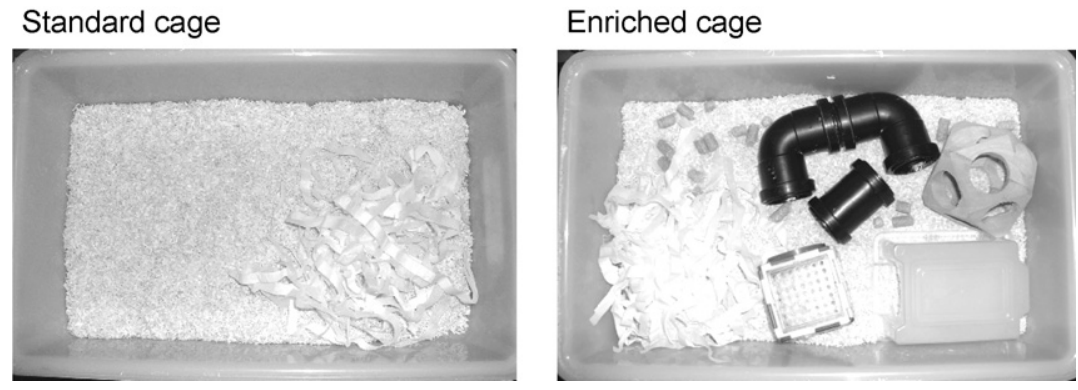

Fig. 1. Standard and enriched cages.

We recorded body weight at weaning and at 3 months. We assessed stereotypic behaviour at Day 88, from videos of the home cage during the first $4 \mathrm{~h}$ of the dark period (when mice were most active). We used one-zero sampling (sample intervals of $1 \mathrm{~min}$ ) to score activity and stereotypic behaviour [11]. Consistent with other authors (e.g. [31,67]), behaviours (other than normal maintenance behaviours, e.g. locomotion, eating, grooming) were defined as stereotypic if they repeated continuously for longer than $10 \mathrm{~s}$, or if an action was repeated three times in succession (e.g. somersaulting).

To assess baseline corticosteroid output, we collected single micturations to assay corticosterone:creatinine (cf. [60]), allowing the assessment of and correction for urinary concentration. At the beginning of the active period (dusk) on Day 89 we placed each mouse into a clean cage and collected urine as it was eliminated. Collection stopped when the mice had produced $0.25 \mathrm{ml}$ or after $50 \mathrm{~min}$ (whichever occurred sooner): a time limit imposed to avoid contaminating the sample with the stress of the collection procedure itself (see e.g. [55]). Samples were stored at $-20^{\circ} \mathrm{C}$, and sent for analysis of corticosterone and creatinine by SCL Laboratories (Stockton-on-Tees)

\subsection{Transfer to non-enriched, standard conditions and subsequent} behavioural/physiological data collection

At 3 months (Day 90), we cleaned out all of the cages and re-housed all mice in STA conditions. We collected urine samples the day after all of the animals were housed in STA conditions (Day 91), and re-assessed stereotypic behaviour 1 month later (Day 120).

At 12 months - much later than originally planned because of problems developing apparatuses - we assessed perseverative tendencies using an extinction task (cf. $[11,61]$ ). We food-deprived the mice for $3 \mathrm{~h}$ from dusk, and then initially trained mice in a spatial discrimination task (shown schematically in Fig. 2a). They were randomly assigned to 'left correct' or 'right correct' and received a food reward for correct responses (1/6th Kellogg's Honey Nut Loop or 1/8th yoghurt sweet: this varied due to individual differences in treat preference). The daily test sessions lasted 20 trials or 20 min-whichever occurred sooner. The mice reached the 'learning criterion' once they performed $80 \%$ correct trials for two consecutive sessions; a $70 \%$ correct response rate was necessary for significantly above chance responding. Perseveration in extinction tasks is manifest as continuing to make previously rewarded responses long after these have stopped being rewarded. During the extinction phase mice were therefore rewarded for the first five correct responses but then not rewarded for any further correct responses in any subsequent daily sessions (cf. [11]). Mice reached the 'extinction criterion' when they chose the previously correct arm on $\leq 65 \%$ of visits on 2 consecutive days (NSD from chance). We recorded number of trials to reach learning and extinction criteria. We also noted the length of each session, and calculated mean inter-trial interval to help us interpret some puzzling motivational results (see below) retrospectively used these data to calculate mean inter-trial interval, since speed of response is affected by perceived reward magnitude (e.g. [63]).

Following the extinction task we assessed the motivation of each mouse to access an enriched cage. We used a 'closed economy' [28] rather than a trial-based set-up, with mice able to access enrichments whenever they chose over the full $24 \mathrm{~h}$ as long as they paid the imposed cost; this design minimised the chances of accidentally missing a period of peak motivation. To do this, a STA and ENR cage were connected by two horizontal white plastic tunnels, each with a clear plastic one-way trapdoor (Fig. 2b). Food and water were provided in the STA cage only. The mice had free access to the ENR cage for 2 days (i.e. the access trapdoor was unweighted). To make ENR-access costly (cf. e.g. [40,43]), we then increased the weight of the trapdoor into the ENR cage every $48 \mathrm{~h}$, by adding two metal washers (total $8.5 \mathrm{~g}$ ) to a bolt attached to it. Exit to the STA cage containing the food and water was always free (i.e. the return door was always unweighted). The daily number of visits to the ENR cage daily was recorded via a counter (Quasar Electronics) connected to the exit trapdoor. The weight at which each mouse failed to enter the ENR cage for $48 \mathrm{~h}$ was deemed its 'maximum price paid'. This maximum price was used to infer each mouse's level of motivation for enrichment $[7,28,46]$ : essentially a 'break-point' measure, but assessed over a longer time period than as typically utilized in conventional operant set-ups (cf. e.g. [40,43]) for the same reason that we used the $24 \mathrm{~h}$ access 'closed economy' design.

After this point was reached, we removed the enrichments, placed the food in this cage and reduced the weight on the trapdoor to the penultimate weight pushed for enrichments. We then increased the weight daily and recorded the number of visits to the food cage each day until the mice did not enter the food cage for $24 \mathrm{~h}$. The aim of this final phase was to use food as a benchmark resource (e.g. [7]), to estimate the maximum weight each mouse was able to push. Controlling for this should ideally help reduce variation in the maximum price for enrichments that merely reflected individual differences in physical strength. The difference in methods between the enrichment and food phases of the task was to use time more efficiently, and to keep within UK Home Office Guidelines on food restriction for mice [17].

\subsection{Opportunistic data collection from 'semi-retired' senescent subjects}

Following the end of the experiment, the mice (less seven individuals that had died) were 'retired' to the stock colony for use in other research projects. They continued to be housed individually, but were all given two large cardboard 'Fun tubes' (Lillico, UK). During this period, when they were 19 months of age, we opportunistically re-recorded their stereotypic behaviour (following the same methods as previously).

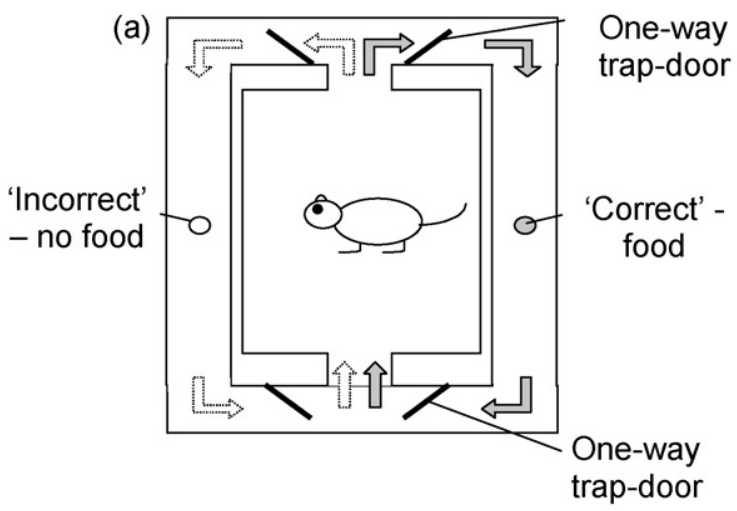

(b)

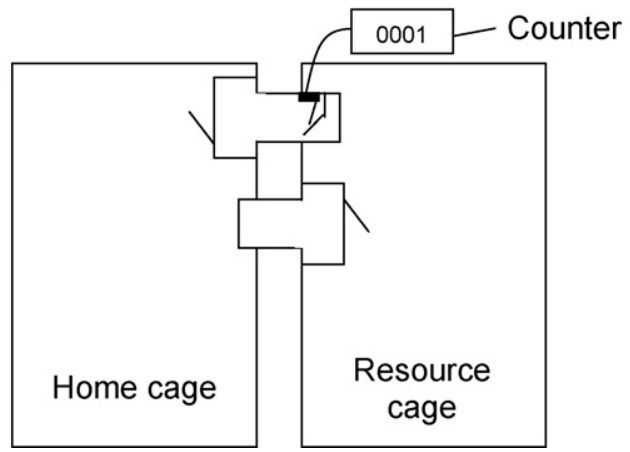

Fig. 2. Schematic representation of (a) the extinction apparatus, and (b) the consumer demand apparatus used to assess motivation for enrichments and food. 


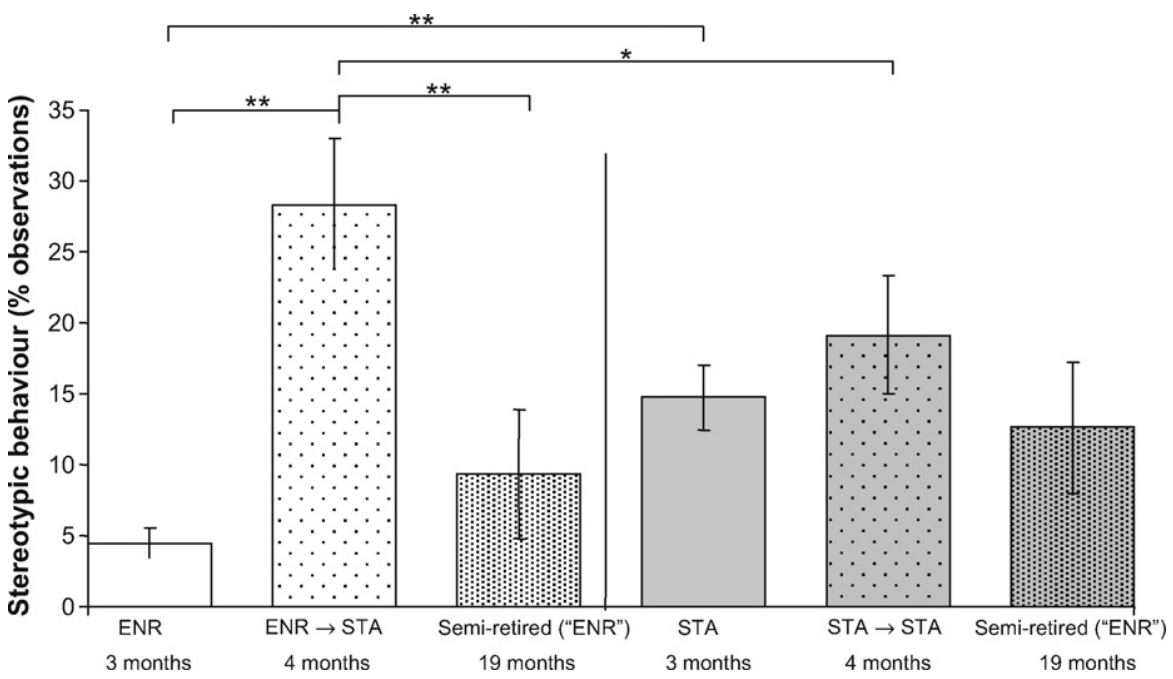

Fig. 3. Stereotypic behaviour (\% observations) at each time point in ENR-reared mice (white columns) and STA-reared mice (grey columns). Error bars show SE mean.

\subsection{Statistical analyses}

Analyses were primarily run using General Linear Models (GLMs) in Minitab (14.11). Rearing environment was our main independent variable of interest. Other blocking factors were sex and litter (and their interactions), with litter being nested in rearing environment, and set as a random effect. To test our hypotheses about the causes for rearing environment effects, the following continuous variables were also investigated as predictors of stereotypic behaviour: corticosterone:creatinine, maximum weight pushed for enrichments (controlling for maximum weight pushed for food), and trials to extinction (controlling for trials to acquisition). Note that where we had measures both before and after transfer to STA conditions (stereotypic behaviour and corticosterone:creatinine), the absolute increases in one were regressed against the absolute increases in the other, controlling for baseline levels (since baseline levels determine the maximum absolute change possible). We also analysed such data using repeated measures GLMs, with mouse identity (identified as a random factor) in the model, as well as the time of sampling.

Further GLMs were run to investigate whether our indices of frustration predicted perseveration under test, where perseveration was a dependent variable. In addition, to investigate whether relationships between perseveration and stereotypic behaviour would be clearer if frustration was statistically partialled out, we added each of our measures of frustration as a covariate to models investigating whether perseveration predicts stereotypic behaviour. Likewise, to investigate whether relationships between frustration and stereotypic behaviour would be clearer if perseveration was statistically partialled out, we added our measure of perseveration as a covariate to models investigating whether frustration predicts stereotypic behaviour. Such tests would reveal whether frustration and perseveration combine to determine overall levels of stereotypic behaviour. Finally, to assess whether motivation and perseveration summate to determine overall levels of stereotypic behaviour, for each sex $\times$ rearing environment group, we ran multiple regressions in which stereotypic behaviour was the dependent variable and our measures of perseveration and frustration, the dependent variables.

In all cases, we confirmed the assumptions of parametric statistics for each analysis, transforming data where necessary. In all models with continuous predictor variables we checked for non-orthogonality, and, where necessary, repeated analyses with sequential instead of adjusted sums of squares, rotating the order of main terms in the model to ensure the consistency of any significant effects were stable (see [13]). To display the results of such GLMs we present the least significant $F$-ratios and $p$-values.

In all bar chart figures, error bars are the SE mean, and significant differences are marked as: ${ }^{*} p<0.05 ;{ }^{* *} p<0.01$. In all figures displaying effects of continuous independent variables, to display the results of such GLMs graphically, we followed the method of Garner (1999) (derived from [13]) for calculating the adjusted values for the covariate term (i.e. adjusted $x$-values), which control for the effects of all other independent variables in the model. This yields a true representation of significant co-variance relationship in models with multiple independent variables. To do this, first, a GLM analysis was performed for the significant main terms or for each of the groups identified by the interaction term: thus, for a significant rearing environment $\times$ covariate interaction, a separate GLM would be performed for the ENR-reared mice and the STA-reared mice. The constant coef ficient was noted as was the coefficient for the covariate term and the Fits were stored. The Fits are the predicted $x$-values which Minitab calculates from the adjusted $x$-values using the standard equation for a slope: $y=m \times x+c$. Since the Minitab regression output provides us with three of these values (' $y$ ' = the Fits; ' $m$ ' = the covariate coefficient, and ' $c$ ' = the constant coefficient) we can calculate the adjusted $x$-values (hereafter termed partialled $x$-values) using the equation: 'partialled $x$-values $=($ Fits/covariate coefficient $)-$ constant coefficient'. The data points on the graph were then created by plotting the (non-partialled) dependent variable values against the partialled $x$-values. The line of best fit was created by plotting the partialled $y$-values (calculated with the equation: 'partialled $y$-values = covariate coefficient $\times$ adjusted $x$-values + constant coefficient' against the partialled $x$-values (the data points themselves were removed from the graph). Graphs drawn using this method do illustrate appropriately how our independent variables predict the dependent variable, once corrected for the effects of blocking factors (unlike plotting simple regressions, which would not correctly represent the models run). However, note that the resulting $x$-axis values are unit-free, not the actual (or transformed) values of the raw data, and nor they comparable between graphs.

\section{Results}

While still housed in their differential rearing conditions, significantly fewer animals performed stereotypic behaviour in the enriched (ENR) cages (17 of 24 in ENR cages vs. 24 of 24 in standard 'STA' cages (Fisher's Exact, $p<0.01$ ). The proportion of observations ENR mice spent in stereotypic behaviour was also lower $\left(F_{1,10}=24.05, p=0.001\right)$-see Fig. 3$)$, a difference persisting even when non-stereotypic animals were excluded $\left(F_{1,10}=16.64\right.$, $p=0.001$ ). However, there were no corresponding environment effects on corticosterone output $\left(F_{1,10}=0.00, p=0.991\right)$; nor did absolute corticosterone levels correlate with stereotypic behaviour $\left(F_{1,27}<0.17, p>0.684\right)$; group means for corticosterone:creatinine ratios are shown in Table 1 . There was a significant sex difference in urinary corticosterone: creatinine $\left(F_{1,31}=234.62, p<0.001\right)$.

Following re-caging and the removal of enrichments from ENR mice, all previously-enriched-housed mice (now termed ENR $\rightarrow$ STA) now came to perform stereotypic behaviour, and they also showed a significant increase in the proportion of observations spent in this behaviour (repeated measures GLM: $F_{2,44}=5.86$, $p=0.004$ ). Indeed ENR $\rightarrow$ STA mice now spent more time performing stereotypic behaviour than did mice housed from birth in STA cages (now termed STA $\rightarrow$ STA): $F_{1,10}=15.02, p=0.001$ ); see Fig. 3 . Thus in this experiment, ENR-rearing was a risk factor for stereotypic behaviour in STA conditions, rather than protective.

Our predictions for this type of scenario were that frustration post-transfer should predict the performance of stereotypic behaviour in ENR $\rightarrow$ STA mice, while perseveration should be no more normal in ENR-reared mice than STA-raised mice. Unexpectedly, ENR $\rightarrow$ STA mice did not have higher absolute corticosterone levels immediately following enrichment-loss, compared to re-caged STA $\rightarrow$ STA mice $\left(F_{1,10}=0.05, p=0.821\right)$; repeated measures analyses also revealed no significant increase in cor- 
Table 1

Mean corticosterone:creatinine ratios at 89 and 91 days.

\begin{tabular}{|c|c|c|c|c|}
\hline & \multicolumn{2}{|c|}{ Corticosterone:creatinine ratio $(\mathrm{nmol} / \mathrm{mmol})-89$ days } & \multicolumn{2}{|c|}{ Corticosterone:creatinine ratio $(\mathrm{nmol} / \mathrm{mmol})-91$ days } \\
\hline & Mean & St. dev. & Mean & St. dev. \\
\hline ENR $\rightarrow$ STA females & 1020.1 & 646.2 & 1336.4 & 1726.7 \\
\hline STA $\rightarrow$ STA females & 924.8 & 629.1 & 1831.3 & 1570.9 \\
\hline ENR $\rightarrow$ STA males & 52.4 & 22.5 & 83.7 & 28.7 \\
\hline $\mathrm{STA} \rightarrow$ STA males & 52.9 & 20.5 & 107.8 & 151.6 \\
\hline
\end{tabular}

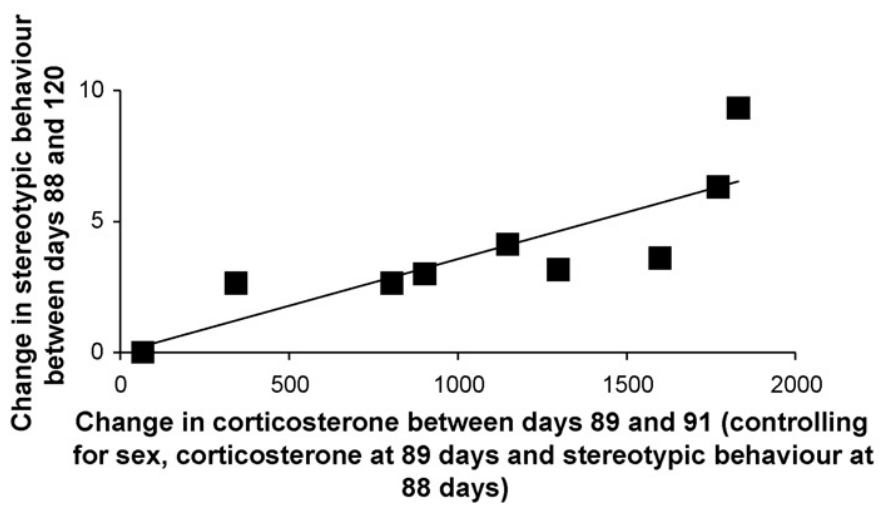

Fig. 4. Correlation between change in corticosterone and change in stereotypic behaviour in ENR $\rightarrow$ STA males following the removal of enrichments (controlling for sex, corticosterone levels at 89 days and stereotypic behaviour at 88 days).

ticosterone levels between Days 89 and 91, even in ENR $\rightarrow$ STA mice. Furthermore, nor did absolute corticosterone levels following re-caging predict the stereotypic behaviour displayed in their new conditions $\left(F_{1,23}<1.60, p>0.219\right)$. However, consistent with our predictions, corticosterone increases in ENR $\rightarrow$ STA males (although not females) did positively predict these animals' increase in stereotypic behaviour following enrichment-removal $($ sex $\times$ rearing environment $\times$ change in corticosterone interaction: $\left.F_{1,11}=6.98, p=0.025\right)$-see Fig. 4 , and furthermore, no such pattern occurred in the STA $\rightarrow$ STA animals.

As also predicted by the Frustration Hypothesis, in the motivation task ENR $\rightarrow$ STA mice pushed greater maximum weights to reach the enriched cage than STA $\rightarrow$ STA mice $\left(F_{1,10}=28.26\right.$, $p<0.01$ ), the break-points of ENR $\rightarrow$ STA mice for enrichment being about 33\% higher than those of STA $\rightarrow$ STA mice (see Fig. 5a). However, unexpectedly, they also pushed greater maximum weights when the resource cage contained just food $\left(F_{1,10}=18.06, p=0.001\right)$, the break-points of ENR $\rightarrow$ STA for food being about $25 \%$ higher than those of STA $\rightarrow$ STA mice (see Fig. 5b). Therefore, when we analysed the maximum weight pushed for enrichments controlling for the maximum weight pushed for food (see Section 2), the originally significant difference between the ENR $\rightarrow$ STA and STA $\rightarrow$ STA animals disappeared $\left(F_{1,10}<0.07, p>0.792\right)-$ see Fig. $5 c$. The group difference in break-point for food was not, however, explained by factors indicating group differences in strength, such as body weight $\left(F_{1,28}<1.11, p>0.300\right)$ or overall activity levels $\left(F_{1,28}<0.78\right.$, $p>0.383$ ), nor by group differences in perseveration (see below), suggesting that it did indeed reflect genuine motivational differences. In addition, motivation for enrichments was predicted by absolute corticosterone levels following transfer to STA cages in the ENR $\rightarrow$ STA animals $\left(F_{1,19}>9.62, p<0.006\right)$ - see Fig. $6 f-$ further suggesting that our measures of frustration reflected the same underlying variable, in mice undergoing a downshift. This result also held when motivation for enrichments was not corrected by motivation to access food $\left(F_{131}>4.15, p<0.05\right)$. Motivation for the enriched cage did not correlate with levels of stereotypic behaviour in the ENR $\rightarrow$ STA animals following the removal of enrichments $\left(F_{1,25}<1.23, p>0.280\right)$-but see below for effects that emerged when perseveration was statistically controlled for

Data from the extinction task tested the underlying role of perseveration in our subjects' stereotypic behaviour. ENR $\rightarrow$ STA and STA $\rightarrow$ STA animals did not differ in the number of trials taken to acquire the discrimination $\left(F_{1,34}=0.5, p=0.497\right)$, and, as expected given that early enrichment did not protect mice against stereotypic behaviour, nor did they differ in the number of trials taken to return to choosing at random in extinction $\left(F_{1,33}=0.07, p=0.792\right)$. The only group difference observed was that ENR $\rightarrow$ STA mice performed trials significantly more quickly at the start of the learning phase $\left(F_{1,33}>7.14, p=0.023\right)$. There was also no overall significant correlation between stereotypic behaviour and trials to extinction in our animals $\left(F_{1,29}=0.24, p=0.631\right)$.

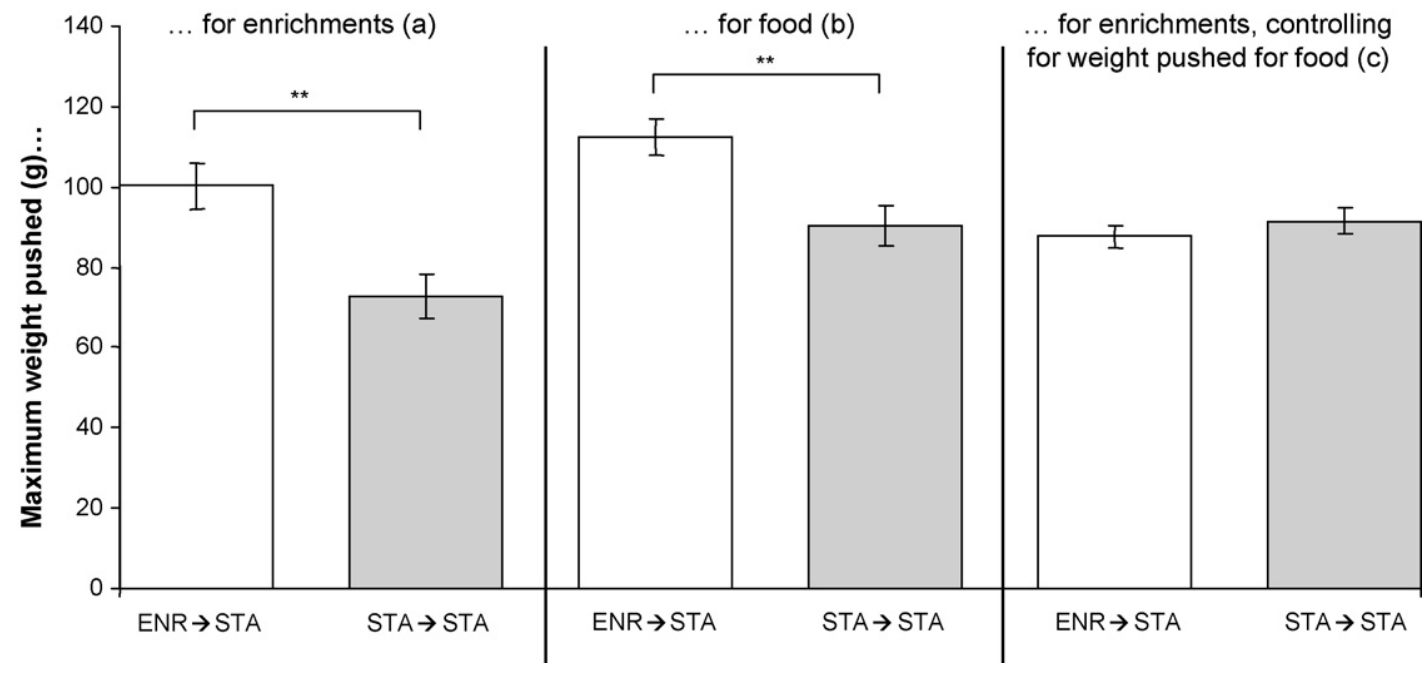

Fig. 5. Maximum weight pushed in the motivation task for enrichments, food, and enrichments controlling for weight pushed for food. Error bars show SE mean. 


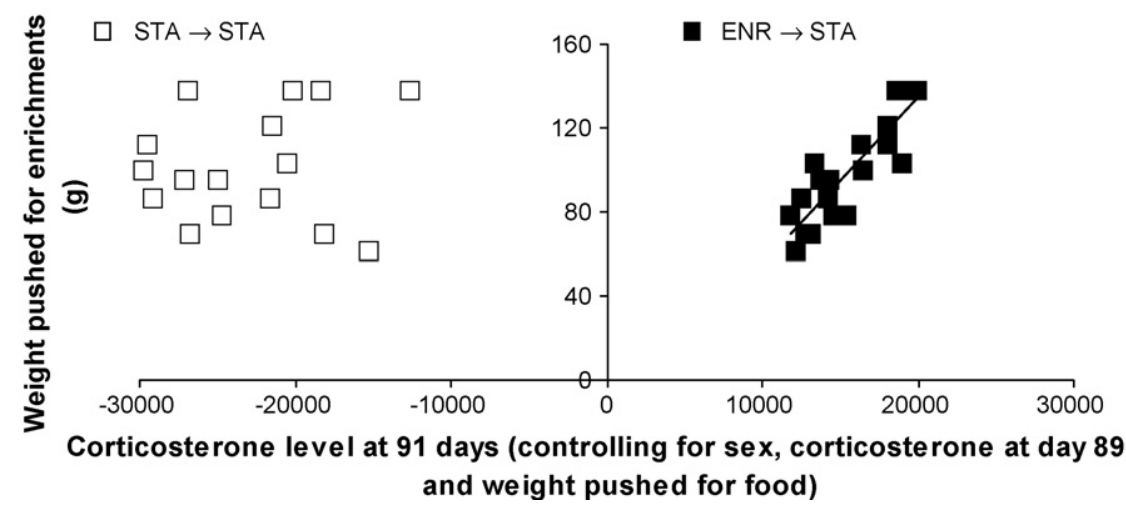

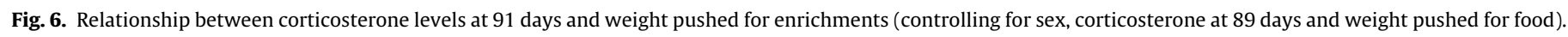

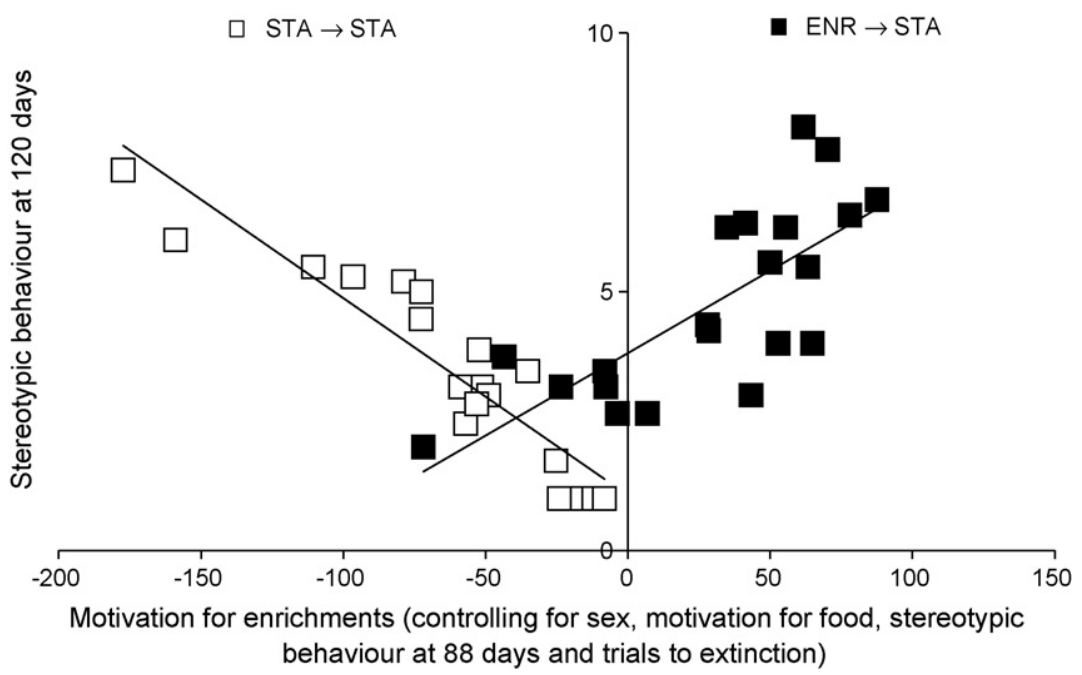

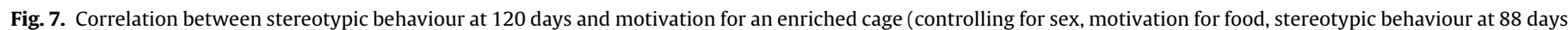
and trials to extinction).

Note that frustration and perseveration did not seem related: perseveration (trials to extinction controlling for trials to acquisition) was unrelated to absolute or changes in corticosterone output post-re-caging $\left(F_{1,25}<0.33, p>0.568\right.$ and $F_{1,24}<0.58, p=0.456$ respectively), and to the maximum weight pushed for enrichments (either blocking for food or not: $F_{1,22}<0.04, p>0.846$ and $F_{1,24}<0.47, p>0.502$, respectively).

Several analyses investigated whether perseveration and frustration acted in concert to influence stereotypic behaviour (see 'statistical methods'). Multiple regressions showed that no combination of frustration measure and motivation measure increased the $R^{2}$ value of models predicting stereotypic behaviour: thus frustration and perseveration did not summate to together better explain overall levels of stereotypic behaviour. GLMs, in which both frustration and perseveration indices were independent variables, to see if one type of measure had clearer effects on stereotypic behaviour when the other type of measure was statistically controlled for, showed that even when frustration effects were partialled out, individual differences in perseveration did not predict individual differences in stereotypic behaviour. However, in contrast statistically controlling for perseveration did reveal additional and interesting correlates of frustration. Thus adding trials to extinction (controlling for trials to acquisition) to a GLM analysing the relationship between stereotypic behaviour and motivation for an enriched cage, revealed a significant rearing environment interaction $\left(F_{1,29}>4.24, p<0.049\right)$, due to a significant positive correlation in the ENR $\rightarrow$ STA mice between the abnormal behaviour and break-point for enrichment, but a very unexpected significant negative correlation in the STA $\rightarrow$ STA animals (see Fig. 7). Finally, our opportunistic testing of the semi-retired animals (aged 19 months) revealed that the change in corticosterone levels between 89 and 91 days positively predicted stereotypic behaviour in all elderly mice, but only if perseveration was statistically controlled for $\left(F_{1,11}>4.97, p<0.05\right)$-see Fig. 8 .

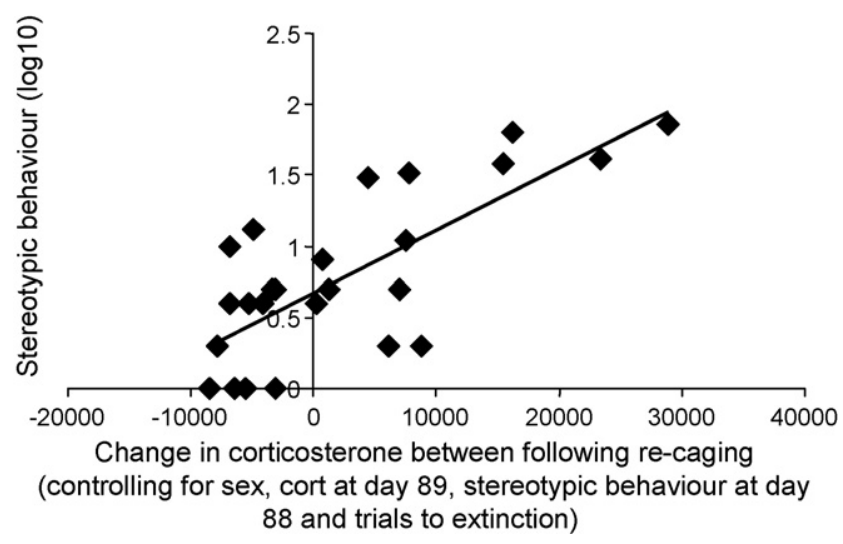

Fig. 8. Correlation between stereotypic behaviour in semi-retired animals and change in corticosterone following re-caging at 3 months (controlling for sex, stereotypic behaviour at 88 days, corticosterone at Day 89 and trials to extinction). 
Table 2

Comparison of results that are consistent/not consistent with the predictions of the Frustration Hypothesis.

\begin{tabular}{|c|c|}
\hline $\begin{array}{l}\text { Results consistent with the Frustration } \\
\text { Hypothesis }\end{array}$ & $\begin{array}{l}\text { Results not consistent with the } \\
\text { Frustration Hypothesis }\end{array}$ \\
\hline $\begin{array}{l}\text { The corticosterone increase in } \\
\text { ENR } \rightarrow \text { STA males following } \\
\text { enrichment-removal predicted these } \\
\text { animals' increase in stereotypic } \\
\text { behaviour over the following month }\end{array}$ & $\begin{array}{l}\text { The change in corticosterone } \\
\text { between } 89 \text { and } 91 \text { days (when } \\
\text { ENR } \rightarrow \text { STA mice experienced } \\
\text { re-caging and } \\
\text { enrichment-removal; } \\
\text { STA } \rightarrow \text { STA mice, just re-caging) } \\
\text { predicted stereotypic } \\
\text { behaviour in all semi-retired } \\
\text { animals (if perseverative } \\
\text { tendencies were controlled for) } \\
\text { Enrichment-removal did not } \\
\text { produce a significant } \\
\text { corticosterone increase in } \\
\text { ENR } \rightarrow \text { STA animals }\end{array}$ \\
\hline $\begin{array}{l}\text { ENR } \rightarrow \text { STA mice pushed a higher } \\
\text { maximum door-weight than STA } \\
\rightarrow \text { STA mice to access an enriched } \\
\text { cage }\end{array}$ & $\begin{array}{l}\text { ENR } \rightarrow \text { STA animals did not } \\
\text { push significantly more weight } \\
\text { to access enrichments, if data } \\
\text { were controlled for weight } \\
\text { pushed for food (because } \\
\text { ENR } \rightarrow \text { STA mice unexpectedly } \\
\text { had a higher break-point for } \\
\text { food) }\end{array}$ \\
\hline $\begin{array}{l}\text { Corticosterone levels following } \\
\text { enrichment-removal predicted } \\
\text { subsequent motivation for } \\
\text { enrichments in ENR } \rightarrow \text { STA mice } \\
\text { (regardless of whether data } \\
\text { corrected for break-point for food) }\end{array}$ & $\begin{array}{l}\text { ENR } \rightarrow \text { STA animals ran more } \\
\text { quickly for sucrose-rich } \\
\text { rewards during the training } \\
\text { trials of the instrumental task }\end{array}$ \\
\hline $\begin{array}{l}\text { Stereotypic behaviour following } \\
\text { enrichment-removal correlated with } \\
\text { break-point for enrichment in } \\
\text { ENR } \rightarrow \text { STA animals (if perseveration } \\
\text { was controlled for); in males, this was } \\
\text { regardless of whether data corrected } \\
\text { for break-point for food }\end{array}$ & $\begin{array}{l}\text { Stereotypic behaviour in } \\
\text { STA-STA animals negatively } \\
\text { correlated with motivation for } \\
\text { enrichments (if perseveration } \\
\text { was controlled for) }\end{array}$ \\
\hline $\begin{array}{l}\text { Perseveration did not account for the } \\
\text { treatment effect on stereotypic } \\
\text { behaviour }\end{array}$ & \\
\hline
\end{tabular}

Table 2 summarises how our results were consistent (or otherwise) with the predictions of the Frustration Hypothesis.

\section{Discussion}

We hypothesised that when early enrichment protects against stereotypic behaviour in animals transferred to non-enriched conditions, as often documented (see Section 1 ), it does so by producing more normally-functioning individuals (Protection Hypothesis); but when it increases later risks of stereotypic behaviour in such animals, as reported in other cases, it does so via abnormally prolonging the activating effects of frustrative non-reward (Frustration Hypothesis). Our enrichments reduced (although they did not prevent) stereotypic behaviour while mice were in these rearing environments, and they also proved reinforcing: thus they were quite successful. After enrichment-removal, enriched-reared subjects then became dramatically more stereotypic, displaying far more stereotypic behaviour than conspecifics raised with no enrichment: the scenario in which we expected frustration to play a major role. The Frustration Hypothesis predicted that in the ENR $\rightarrow$ STA group, high frustration would predict great increases in stereotypic. We inferred frustration from elevated corticosterone output and stronger motivations to access environmental enrichments, respectively assessed via the non-invasive collection of excreted steroids in single micturations, and the 'break-point' reached by mice performing an increasingly demanding appetitive task. In ENR $\rightarrow$ STA mice, urinary corticosterone:creatinine following enrichment-removal did correlate with maximum weights pushed for enrichment, suggesting that in the group experiencing the downshift in environmental conditions, these endocrine and behavioural indices were indeed related.

Several predictions of the Frustration Hypothesis were met, although our treatment groups did not quite differ as expected. Increases in corticosterone in ENR $\rightarrow$ STA males (though not females) following enrichment-removal predicted increases in stereotypic behaviour over the following month. These results are consistent with previous studies showing that corticosterone responses after weaning predict later stereotypic behaviour [66] Furthermore, in ENR $\rightarrow$ STA animals only, stereotypic behaviour following enrichment-removal correlated with motivations for enrichments-provided that perseverative influences on stereotypic behaviour were statistically controlled for. It is unlikely that these results simply reflected increases in, respectively, activity or the capacity to work harder, because corticosterone levels did not correlate with either stereotypic behaviour or overall activity, and nor did the STA $\rightarrow$ STA group show a corresponding positive correlation between corticosterone and motivation for enrichments. Finally, ENR $\rightarrow$ STA animals as a group pushed higher maximum weights than STA $\rightarrow$ STA mice to gain access to an enriched cage - a lasting effect still evident 10 months after differential rearing. This index became non-significant when we controlled for break-points displayed to reach a cage containing food, because of the ENR $\rightarrow$ STA group's unexpectedly elevated maximum weights pushed for food. This statistical correction was aimed at controlling for individual differences in physical strength which might have added nonsystematic error. However, because there were no a priori reasons to think ENR $\rightarrow$ STA mice should systematically be stronger, and nor in practice were they heavier, our suspicion is that this correction was actually inappropriate, and that our findings instead reflect some surprising, generalized motivational differences. This idea, and how it might be tested, is discussed in more detail below. A further puzzle was that ENR $\rightarrow$ STA mice did not show greater corticosterone increases at enrichment-removal than STA $\rightarrow$ STA mice did at re-caging. Again, what might have caused this is discussed below.

Thus in summary, within ENR $\rightarrow$ STA mice, corticosterone and motivational indices were thus coupled in the way we predicted, and in a manner not seen within STA $\rightarrow$ STA mice; these indices also predicted stereotypic behaviour in these animals. Whether ENR $\rightarrow$ STA mice were more frustrated than STA $\rightarrow$ STA mice by unenriched cages was rather less evident. We suspect, however, that this reflects problems with the data as collected. With respect to our endocrine index, urine samples were only taken once, $24 \mathrm{~h}$ after re-caging, which perhaps did not allow enough time for the downshift to induce frustration in ENR $\rightarrow$ STA mice, or for this to be manifest as excreted corticosterone in urine-see, for example, a study by Kawasaki and Iwasaki [18] for a case of surprising non-reward not elevating corticosterone until the third day of extinction. Turning to our measure of motivation for enrichment, here the puzzle was not a lack of treatment effect but rather the surprising group difference in maximum weight pushed for food. The possibility that enriched-reared mice are simply physically stronger cannot completely be ruled out, and further work should investigate this. However, there are two alternative motivational explanations for this finding, one of which concords with our assumption that working for enrichment reflects frustration in non-enriched cages. The first is that reduced motivations for both enrichment and food in the STA $\rightarrow$ STA animals reflected aboulia, a common symptom in neurodegenerative and neuropsychiatric disorders [1]. This could explain why these animals also ran more slowly for sucrose-rich treats during the initial trials of the instrumental task (see Section 3). The second possibility is that the mice working hardest for the resource cage, regardless of its contents, were simply those most motivated to escape from the standard 
non-enriched cage-see Nevison et al. [31] for links between escape motivations and stereotypic behaviour in mice, and Nicol and Guilford [32] for enhanced extra-cage exploration induced by frustration. We suspect that the latter is correct, but both ideas now need direct test.

Additional interesting findings were as follows. First, having a large immediate corticosterone reaction to the type of environmental change experienced here predicted the development of stereotypic behaviour but only in some circumstances. One example was that corticosterone reactions to environmental change predicted stereotypic behaviour only in ENR $\rightarrow$ STA mice. One possibility, as discussed above, is that our sampling failed to detect group differences in corticosteroid output that emerged after $24 \mathrm{~h}$, with such increases being the true predictors of stereotypic behaviour. However, it is equally possible that our data instead reveal individual risk factors, or 'endophenotypes' (cf. [12]) that only predict clinically-relevant outcomes, here stereotypic behaviour, in particular contexts, here downshifts in environmental quality. Consistent with this, all mice with large corticosterone reactions to environmental change, regardless of rearing condition, displayed higher levels of stereotypic behaviour once senescent: an effect evident an impressive 16 months after endocrine sampling. A further result of interest was that impaired behavioural inhibition (as would induce perseveration) was statistically independent of the frustration-related measures. In addition, in contrast with other studies that have found a relationship between stereotypic and perseverative behaviour $[11,61]$ it had no main effects on stereotypic behaviour, nor did it increase the variance explained in the multiple regression models. However, it usefully partitioned out variance in some GLM models, suggesting that it was playing some minor and subtle role in the aetiology of stereotypic behaviour. Any replications of this study should investigate these effects further, and also assess perseveration while subjects are still differentially housed, as well as sooner after transfer to standard conditions.

The dramatic increases in stereotypic behaviour induced by enrichment-removal in this experiment contrast strongly with the long-term protection sometimes reported in other studies (see Section 1). Further work is necessary to identify exactly why early enrichment sometimes confers long-term protection against stereotypic behaviour. Although the results of this particular experiment did not allow this to be investigated, they do suggest a hypothesis for future test. Our enrichments were somewhat successful, but they did not prevent stereotypic behaviour from emerging (initially 17 of the 24 ENR-housed animals performed it, even prior to transfer to STA cages) and nor did they make mice less perseverative under test. We therefore suspect that whether naturalistic complex rearing environments enhance stereotypic behaviour after a frustrating downshift in conditions, as seen here, or instead protect against it as recorded in wild-caught animals, depends on how efficacious that previous environment was at ensuring normal forebrain development.

\section{In conclusion}

Our data confirm that enriched-reared animals are sometimes predisposed to develop more severe, time-consuming stereotypic behaviour in non-enriched conditions than animals raised from birth in such environments. Other changes in these downshifted animals were greater motivations to access enrichments (along with unexpectedly enhanced motivations to access an empty cage containing food), evident even 10 months after differential rearing; a coupling of corticosterone responsiveness and motivation for enrichments, and close links between these indices and the development of stereotypic behaviour. All these effects now require replication and further study, in particular using the more thor- ough sampling of HPA responses after the downshift, and also more typically socially-housed animals. However, these findings do suggest, for the first time, that individual predispositions relating to stress responsiveness predict the enhanced performance of stereotypic behaviour induced by enrichment-removal (as well as the enhanced performance of stereotypic behaviour in senescence). In practical and welfare terms, although enrichment is an important method of refining housing and improving rodent welfare [35], we also recommend that early enrichment should be used with caution if lifelong enrichment cannot be guaranteed: we particularly advise that early enrichment of the type used here should not be given to pre- and peri-weaning mice if they are likely to experience downshifts in environmental conditions later in life.

\section{Acknowledgements}

N. Latham was funded by the Universities Federation for Animal Welfare. We would like to thank Ros Clubb, Judith Lloyd and Julian for their assistance during the project, and Jamie Dallaire and Megan Jones for their constructive comments during the preparation of this manuscript.

\section{References}

[1] Al-Adawi S, Dawe G, Al-Hussaini A. Aboulia: neurobehavioural dysfunction of dopaminergic system? Med Hypotheses 2000;54:523-30.

[2] Bayne K, Hurst J, Dexter S. Evaluation of the preference to and behavioral effects of an enriched environment on male rhesus monkeys. Lab Anim Sci 1992;42:38-45.

[3] Bolhuis J, Schouten W, Schrama J, Wiegant V. Effects of rearing and housing environment on behaviour and performance of pigs with different coping characteristics. Appl Anim Behav Sci 2006;101:68-85

[4] Cooper J, Ödberg F, Nicol C. Limitations of the effectiveness of environmental improvement in reducing stereotypic behaviour in bank voles (Clethrionomys glareolus). Appl Anim Behav Sci 1996;48:237-48.

[5] Cottone P, Sabino V, Steardo L, Zorrilla E. Intermittent access to preferred food reduces the reinforcing efficacy of chow in rats. Am J Physiol Regul Integr Comp Physiol 2008;295:R1066-76.

[6] Crespi L. Quantitative variation of incentive and performance in the white rat. Am J Psychol 1942;55:467-517.

[7] Dawkins M. Battery hens name their price: consumer demand theory and the measurement of ethological needs. Anim Behav 1983;31:1195-205.

[8] Day J, Burfoot A, Docking C, Whittaker X, Spoolder H, Edwards S. The effects of prior experience of straw and the level of straw provision on the behaviour of growing pigs. Appl Anim Behav Sci 2002;76:189-202.

[9] Dixon L, Duncan I, Mason G. What's in a peck? Using fixed action pattern morphology to identify the motivational basis of abnormal feather-pecking behaviour. Anim Behav 2008;76:1035-42.

[10] Frith C, Done J. Stereotyped responding by schizophrenic patients on a twochoice guessing task. Psychol Med 1983;13:779-86.

[11] Garner J, Mason G. Evidence for a relationship between cage stereotypies and behavioural disinhibition in laboratory rodents. Behav Brain Res 2002;136:83-92.

[12] Gottesman I, Gould T. The endophenotype concept in psychiatry: etymology and strategic intentions. Am J Psychol 2003;160:636-45.

[13] Grafen A, Hails R. Modern statistics for the life sciences. Oxford: Oxford University Press; 2002

[14] Hadley C, Hadley B, Ephraim S, Yang M, Lewis M. Spontaneous stereotypy and environmental enrichment in deer mice (Peromyscus maniculatus): reversibility of experience. Appl Anim Behav Sci 2006;97:312-22.

[15] Hansen S, Malmkvist J, Palme R, Damgaard B. Do double-cages and access to occupational materials improve the welfare of farmed mink? Anim Welf 2007;16:63-76.

[16] Haskell M, Mendl M, Lawrence A, Austin E. The effect of delayed feeding on the post-feeding behaviour of sows. Behav Process 2000;49:85-97.

[17] Home Office. Home office guidance note: water and food restriction for scientific purposes; 2003. Available online at: http:// scienceandresearchhomeofficegovuk/animal-research/publications-andreference/publications/code-of-practice/housing-of-animals-breeding/ waterfoodguidancepdf?view=Binary.

[18] Kawasaki K, Iwasaki T. Corticosterone levels during extinction of runway response in rats. Life Sci 1997;61:1721-8.

[19] Keiper R. Causal factors of stereotypies in caged birds. Anim Behav 1969;17:114-9.

[20] Kolb B, Whishaw I. Brain plasticity and behaviour. Annu Rev Psychol 1998;49:43-64.

[21] Latham N, Mason G. Maternal deprivation and the development of stereotypic behaviour. Appl Anim Behav Sci 2008;110:84-108. 
[22] Lewis M, Presti M, Lewis J, Turner C. The neurobiology of stereotypy 1: environmental complexity. In: Mason G, Rushen J, editors. Stereotypic animal behaviour: fundamentals and applications to welfare. Wallingford: CAB International; 2006.

[23] Lyons D, Fong K, Schrieken N, Levine S. Frustrative nonreward and pituitary-adrenal activity in squirrel monkeys. Physiol Behav 2000;71:559-63.

[24] Mason G. Are wild-born animals 'protected' from stereotypies? In: Mason G Rushen J, editors. Stereotypies in captive animals. 2nd edition Wallingford: CAB International; 2006.

[25] Mason G, Clubb R, Latham N, Vickery S. Why and how should we use environmental enrichment to tackle stereotypic behaviour? Appl Anim Behav Sci 2007; $102: 163-88$.

[26] Mason G, Cooper J, Clarebrough C. Frustrations of fur-farmed mink. Nature 2001;410:35-6.

[27] Mason G, Latham N. Can't stop, won't stop: is stereotypy a reliable animal welfare indicator? Anim Welf 2004;13(Suppl.):S57-69.

[28] Mason G, McFarland D, Garner J. A demanding task: assessing the needs of captive animals. Anim Behav 1998:55:1071-5.

[29] McBride S, Hemmings A. Altered mesoaccumbens and nigro-striatal dopamine physiology is associated with stereotypy development in a non-rodent species. Behav Brain Res 2005;159:113-8.

[30] Mora F, Segovia G, del Arco A. Aging, plasticity and environmental enrichment: structural changes and neurotransmitter dynamics in several areas of the brain. Brain Res Rev 2007;55:78-88.

[31] Nevison C, Hurst J, Barnard C. Why do male ICR(CD-1) mice perform bar-related (stereotypic) behaviour? Behav Process 1999;47:95-111.

[32] Nicol C, Guilford T. Exploratory activity as a measure of motivation in deprived hens. Anim Behav 1991;41:333-41.

[33] Nithianantharajah J, Hannan A. Enriched environments, experiencedependent plasticity and disorders of the nervous system. Nat Rev Neurosci 2006;7:697-709.

[34] Ödberg F. The influence of cage size and environmental enrichment on the development of stereotypies in bank voles (Clethrionomys glareolus). Behav Process 1987; $14: 155-73$.

[35] Olsson A, Dahlborn K. Improving housing conditions for laboratory mice: a review of 'environmental enrichment'. Lab Anim 2002;36:243-70.

[36] Papini M. Comparative psychology of surprising non-reward. Brain Behav Evol 2003;62:83-95.

[37] Pecoraro N, Timberlake W, Tinsley M. Incentive downshifts evoke search behavior in rats (Rattus norvegicus). J Exp Psychol Anim Behav Process 1999;25:153-67.

[38] Powell S, Newman H, McDonald T, Bugenhagen P, Lewis M. Development of spontaneous stereotyped behavior in deer mice. Dev Psychobiol 2000;37:100-8.

[39] Presti M, Lewis M. Striatal opioid peptide content in an animal model of spontaneous stereotypic behavior. Behav Brain Res 2005;157:363-8.

[40] Pryce C, Dettling A, Spengler M, Schnell C, Feldon J. Deprivation of parenting disrupts development of homeostatic and reward systems in marmoset monkey offspring. Biol Psychiatry 2004;56:72-9.

[41] Renner M, Rosenzweig M. Enriched and impoverished environments: effects on brain and behaviour. New York: Springer; 1987.

[42] Robbins T, Mittleman G, O’Brien J, Winn P. The neurobiological significance of stereotypy induced by stimulant drugs. In: Cooper S, Dourish C, editors. The neurobiology of stereotyped behaviour. Oxford: Clarendon Press; 1990.

[43] Rüedi-Bettschen D, Pedersen E-M, Feldon J, Pryce C. Early deprivation under specific conditions leads to reduced interest in reward in adulthood in Wistar rats. Behav Brain Res 2005;156:297-310.

[44] Rushen J, Lawrence A, Terlouw C. The motivational basis of stereotypies. In: Lawrence A, Rushen J, editors. Stereotypic behaviour: fundamentals and applications to welfare. Wallingford: CAB International; 1993. p. 41-64.

[45] Sandson J, Albert M. Perseveration in behavioural neurology. Neurology 1987; $37: 1736-41$
[46] Sherwin C, Nicol C. Reorganisation of behaviour in laboratory mice, Mus musculus, with varying cost of access to resources. Anim Behav 1996;51:1087-93.

[47] Shyne A. Meta-analytic review of the effects of enrichment on stereotypic behavior in zoo mammals. Zoo Biol 2006;25:317-37.

[48] Stout S, Boughner R, Papini M. Re-examining the frustration effect in rats: after effects of surprising reinforcement and non-reinforcement. Learn Motiv 2003;34:437-56.

[49] Swaisgood R, Shepherdson D. Environmental enrichment as a strategy for mitigating stereotypies in zoo animals: a literature review and meta-analysis. In: Mason G, Rushen J, editors. Stereotypic animal behaviour: fundamentals and applications to welfare. Wallingford: CABI; 2006. p. 256-85.

[50] Swaisgood R, Shepherdson D. Scientific approaches to enrichment and stereotypies in zoo animals: what's been done and where should we go next? Zoo Biol 2005;24:499-518.

[51] Tanimura Y, Lewis M. Indirect basal ganglia-mediated mediation of repetitive behaivour: attenuation by adenosine receptor agonists. Behav Brain Res 2010;210(1):116-22.

[52] Tanimura Y, Yang M, Lewis $M$. Procedural learning and cognitive flexibility in a mouse model of restricted, repetitive behaviour. Behav Brain Res 2008;189(2):250-6.

[53] Terlouw E, Lawrence A, Illius A. Relationship between amphetamine and environmentally induced stereotypies in pigs. Pharmacol Biochem Behav 1992;43:347-55.

[54] Tilly S, Dallaire J, Mason G. Too old to care? Enrichment resistance stereotypic behaviour in 'middle-aged' mice is linked with reduced motivation for environmental enrichment. Anim Behav; submitted for publication.

[55] Touma C, Sachser N, Mostl E, Palme R. Effects of sex and time of day on metabolism and excretion of corticosterone in urine and feces of mice. Gen Comp Endocrinol 2003;130:267-78.

[56] Turner C, Lewis M. Environmental enrichment: effects on stereotyped behavior and neurotrophin levels. Physiol Behav 2003;80:259-66.

[57] Turner C, Lewis M, King M. Environmental enrichment: effects on stereotyped behavior and dendritic morphology. Dev Psychobiol 2003;43:20-7.

[58] Turner C, Presti M, Newman H, Bugenhagen P, Crnic L, Lewis M. Spontaneous stereotypy in an animal model of Down syndrome: Ts65Dn mice. Behav Genet 2001:31:393-400.

[59] Turner M. Towards an executive dysfunction account of repetitive behaviour in autism. In: Russell J, editor. Autism as an executive disorder. New York: Oxford University Press; 1997. p. 57-100.

[60] Van Loo P, Kruitwagen C, Koolhaas J, Van de Weerd H, Van Zutphen L, Baumans $\mathrm{V}$. Influence of cage enrichment on aggressive behaviour and physiological parameters in male mice. Appl Anim Behav Sci 2002;76:65-81.

[61] Vickery S, Mason G. Stereotypy and perseverative responding in caged bears: further data and analysis. Appl Anim Behav Sci 2005;91:247-60.

[62] Wang L, Simpson H, Dulawa S. Assessing the validity of current mouse genetic models of obsessive-compulsive disorder. Behav Pharmacol 2009:20:119-33.

[63] Watanabe M, Cromwell H, Tremblay L, Hollerman J, Hikosaka K, Schultz W. Behavioral reactions reflecting differential reward expectations in monkeys. Exp Brain Res 2001;140:511-8.

[64] Wiedenmayer. Causation of the ontogenic development of stereotypic digging in gerbils. Anim Behav 1997;53:461-70.

[65] Wiegmann D, Wiegmann D, Waldron F. Effects of a reward downshift on the consummatory behavior and flower choices of bumblebee foragers. Physio Behav 2003;79:561-6.

[66] Würbel H, Stauffacher M. Age and weight at weaning affects corticosterone levels and development of stereotypies in ICR mice. Anim Behav 1997:53:891-900.

[67] Würbel H, Stauffacher M, Holst Dv. Stereotypies in laboratory mice-quantative and qualitative description of the ontogeny of wire-gnawing and jumping in Zur:ICR and Zur:ICR nu. Ethology 1996;102:371-85.

[68] Zimmerman P, Koene P, van Hooff J. Thwarting of behaviour in different contexts and the gakel call in the laying hen. Appl Anim Behav Sci 2000;69: 255-64. 